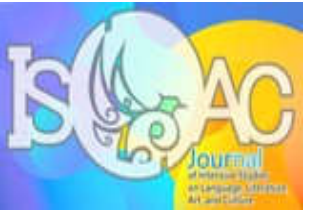

ISLLAC : Journal of Intensive Studies on Language, Literature, Art, and Culture

Volume 2 Issue. 1, 2018

Journal homepage : http://journal2.um.ac.id/index.php/jisllac

\title{
A STUDY ON THE PHENOMENA IN LESU-LULI'S POETRY IN BOBONARO MUNICIPALITY
}

\author{
Agostinho dos Santos Gonçalves, Anna Isabela Sanam, and Paulina Dau De Jesus Soares* \\ Instituto Superior Cristal, Dili-Timor Leste
}

ARTICLE INFO

Keyword:

Phenomenon,

poetry,

lesu - luli

\begin{abstract}
A B S T R A C T
The aim of this research was to describe the history of Lesu-luli and to find the intrinsic elements in Lesu-luli's Poetry. This research was a phenomenological research that using the descriptive method. In this study, the primary data was the script of lesu - luli's poetry while the secondary data was the source text, such as literary theory books, the results of another literature research about poetry and culture, as well as the source from the internet. In this study, there were four informants. The data gathering from the informants was analyzed in three steps, namely data reduction and translating, data presentation and conclusion or verification. Based on the result of this study the history of "lesu-luli" is coming from the name of two grandfathers namely Mau Lesu and Lesu Tali. Mau Lesu came from uma Slelo while Lesu Tali came from uma Bere Ubu. Both of the grandfathers were a captain and a major. They had played the important role to struggle and liberate for the tradition of lesu luli. This struggle involved the eight households (that now become the eight of uma lisan or uma lulik) and also the kings. The kings were two peoples namely Talentuand Kornel. Talentu came from uma Bero Mau while Kornel came from uma Kali Ubu. Lesu - luli not only a sacred stone without meaning. Peoples in Meligo village made this place as a place where the people could ask the blessing of the ancestors and God. This was a culture and tradition that regularly conducted every year around September or October. Peoples in Meligo village believed that if the ceremony of lesu - luli was not celebrated, it would cause died, disaster, bad seeds, and drought (dry season). The intrinsic elements found in lesu - luli's poetry were: (1) Structure. In the structural analysis, the writer found two elements line and stanza. The types of the stanza in lesu - luli's poetry were a triplet, the quatrain, and the cinquain/quintet stanza. (2) Sound. The most type of sound found in lesu - luli's poetry was ended rhyme sound. (3) Figurative language or diction. The style of language or diction that found in lesu - luli's poetry was a formal language and the selection of words in this poem was very religious. Finally, the writer conclude that a culture must be protected because a culture is a foundation of human life.
\end{abstract}

\section{INTRODUCTION}

Literature is a creative writing of language, period or culture which recognized the artistic value and has qualities of language . As stated by Klarer (2004: pg.1) literature is referred to as the entirety of written expression, with the restriction that not every written document can be categorized as literature in the more exact sense of the word. The definitions, therefore, usually include additional adjectives such as "aesthetic" or "artistic" to distinguish literary works from texts of everyday use such as telephone books, newspapers, legal documents, and scholarly writings.

A literature and a text cannot be separated from each other. Etymologically, the Latin word "litteratura" is derived from "littera" (letter), which is the smallest element of alphabetical writing. The word text is related to "textile" and can be translated as "fabric": just as single threads form a fabric, so words and sentences form a meaningful and coherent text. Therefore, the origins of the two central terms

\footnotetext{
"Corresponding author.

E-mail addresses: dossantosgoncalvesagostinho@gmail.com (Agostinho dos Santos Gonçalves), eeeisabela166@gmail.com (Anna Isabela Sanam)
}

ISSN : 2597-7385 (Online) - ISLLAC : Journal of Intensive Studies on Language, Literature, Art, and Culture is licensed under Creative Commons Attribution-ShareAlike 4.0 International License (http://creativecommons.org/licenses/BY/4.0/).

14 | ISLLAC : Journal of Intensive Studies on Language, Literature, Art, and Culture 
do not help in defining literature or text. It is more enlightening to look at literature or text as cultural and historical phenomena and to investigate the conditions of their production and reception in various genres of literature.

The term genre usually refers to one of the three classical literary forms of epic, drama, or poetry. This categorization is slightly confusing because the epic normally occurs in verse too, but here it is not classified as poetry. Actually, the three genres above are the old classification. The tendency today is to abandon the term "epic" and introduce "prose fiction" for the relatively young literary forms of the novel and the short story. Klarer (2004) explained that the recent classifications prefer the terms fiction, drama, and poetry as designations of the three major literary genres, as well as those of film.

Poetry is one of the oldest genres in literary history. As stated by Klarer (2004: pg. 27) Poetry is closely related to the term "Iyric," which derives etymologically from the Greek musical instrument "lyra" ("Iyre" or "harp") and points to an origin in the sphere of music. In addition, Klarer also argued that the genre of poetry is often subdivided into the two major categories of narrative and lyric poetry. Narrative poetry includes genres such as the epic long poem, the romance and the ballad, which tell stories with clearly developed and structured plots. While lyric poetry is a formal type of poetry which expresses personal emotions or feelings, typically spoken in the first person and mainly concerned with one event, impression, or idea (Puspitoningrum \& Rahmayantis, 2017).

As a newly independent country, literature has a great role and benefit in the struggle for East Timor's independence. One of the literature that greatly influence East Timor's independence is the culture. People in this country has a culture to express sacred words to ask God's blessings. People in Timor Leste call it "hamulak". Such as poetry "hamulak" also contains lyrics, meter, rhythm, and sounds. Besides that, it is one of the cultures in Timor Leste which has been existing from generation to generation. Therefore, most of the people in this country very respectful of the culture itself.

Meligo is one of the small villages in Bobonaro municipality which has a sacred stone namely "lesu - Iulf'. This sacred stone has its history and people in Meligo believed that this sacred stone able to keep the people away from the natural disaster. Every year people bring the worship to this sacred stone and expressing sacred words to ask blessings from the ancestors (hamulak). Peoples believe that the more pray and worship, the ancestors will get the light and salvation. So otherwise, the ancestors also will always pray and give the protection.

As quoted from Irish that "a people without the knowledge of their past, origin, and culture is like a tree with no roots", here, the writer is very motivated to explore more about the culture in Meligo village especially about the people believed in "lesu - Iulf". Therefore, the title of this research is "A Study on the Phenomena in "Lesu-Luli's Poetry" in Bobonaro Municipality".

\section{THEORETICAL FRAMEWORK}

Literature was the art which imitates life in words with the twin objectives of entertaining and edifying. There has always been the yet unresolved argument as to whether literature inheres in the matter, subject or object that it concerns itself with or in its manner or style of expressing this matter of focus. While these arguments are valid in locating literature in a particular space in the array of other written forms produced by the author, it is the major characteristics of the art that defines it most precisely. In this regard, literature is best seen as the body of work (written or oral) in which man's record of his experiences is given artistic form.

Accordingly, literature embodies the most basic issues of life which the American poet, Ezra Pound (Osakwe: 2015), has seen "the news that remains news" because of its perennial currency. It is in this vision that lies the quality of universality of the art. Besides, the literary cosmos is best marked by its qualities of imagination, creativity, and suggestiveness. These qualities are most explicitly discernible in Poetry which is the oldest of the major forms or genres of literature.

Literature represents and pictures out various aspects of life. According to Wellek and Warren (1956: 3 ) in Sari, the literature mirrors and expresses life that is even more ambiguous. It means that the literature is come up from the events happen in the society. In literature, the author presents a work to delivers his or her ideas to the reader. Here, it can be understood that in every work has its own characteristic dan authors' objective.

Jones (1986: 1) in Sari stated that literature, in its, broader sense includes all written materials. Since the general grouping of materials will be in a very various number; history books, philosophical works, novel, poems, plays, scientific articles, dictionaries, magazines, school textbooks, etc. Thus, he divides those general group into two.

Furthermore, Long (1991:3) in Sari stated that literature in the broader sense, perhaps, literature means simply the written records of the race, including all its history and science, as well as its poems and 
novels; in the narrow sense literature in the artistic record of life, and most of our writing is excluded from it, just as the mass of our buildings, mere shelter from and from cold, are excluded from architecture.

Robert Frost stated that "A poem begins with a lump in the throat, a home-sickness or a lovesickness. It is a reaching-out toward expression; an effort to find fulfillment. A complete poem is one where the emotion has found its thought and the thought has found the words." While William Wordsworth argued that poetry was the spontaneous overflow of powerful feelings. In additional he also stated that poetry was the recollection of an emotion, which causes a new emotion.

Furthermore, Mathew Arnold in Baer argued that poetry is simply the most beautiful, impressive, and widely effective mode of saying things. Added also by Stageberg \& Anderson in Baer that when we read a poem something happens to us. They bring to life a group of images, feelings, and thoughts.

There were some elements of poetry, namely (Klarer: 2004):(1) structure which consists of poetic line, stanza, enjambment, placement, verse, capitalization and Punctuation, (2) sound: rhythm, meter, end rhyme (internal rhyme, rhyme scheme, assonance, consonance, alliteration, onomatopoeia, repetition), (3) imagery: precise language, sensory details,

Yesufu, A. R et al (2006) presented the major forms or types of poetry as follows: the epic; the ballad; the ode; the sonnet; the elegy; and the lyric.

The epic is a poem composed or written on a grand scale, usually in many separate books or volumes, concerned with the exploits of some great national, historical or legendary character or hero. In other words, an epic celebrates in the form of a continuous narrative the feats of one or more heroic characters of history or tradition. Accordingly, as a rule, the epic treats a theme of lofty nature and consequently, its characters are usually of high social standing or are very powerful forces. As is to be expected, the narrative of an epic is presented in such a way that the actions of the subject intimate and comment on the values and destiny of a particular people or race in spite of its episodic nature.

There are two major types of the epic, namely: folk and art epics. A primary epic is a type that draws its sustenance mainly from the oral tradition of a people hence the label 'folk', while the secondary epic is a modification and reorganized version by identifiable or known authors. This latter type is, as a result of its very basis and nature, written with much literary sophistication by poets who imitate the primary epic in both subject and manner.

Epics share a set of common general characteristics and conventions as follows:

1. The poet commences his narration by stating his theme and invokes the Muse to inspire and instruct him in his task

2. The story begins 'in medias res', that is in the middle of things and proceeds to recount the great deeds of the heroes with objectivity.

3. The action in which supernatural forces participate is one, great and entire

4. The story is of great length and scope with the action taking place over a long period of time and extending over several nations, the world of the poet's day or the imagined universe.

5. The hero who is a person of great stature and legendary and historical significance and performs superhuman actions is more of the concern of the audience or reader because he symbolizes the aspirations and destiny of his nation or race.

6. The narrative style is grand and alternates between the sublime or sustained elevation and grand simplicity.

7. The story includes elaborate formal speeches by the main characters.

8. The constituent episodes of narrative easily arise from the main story and, as a result, there are no parts that could be detached from it without loss to the whole.

9. Epic poet incorporates a long list of warriors, armies, war machines which necessitate the employment of the fitting vehicle of the epic simile or extended comparison.

The ballad, one of the earliest form of poetry, is a song that tells a story or conversely, a story told through song. Thus a ballad is a short narrative poem, adapted for singing, simple in plot and metrical in structure, divided into stanzas of four lines (quatrains) rhyming alternately and characterized by complete impersonality as far as the author or singer is concerned.

As in the epic, there are two main types of the ballad, namely: the folk ballad (also referred to as the popular or traditional ballad) and the art or literary ballad. These terms equally intimate the origins and nature of this type of poetry similar to the distinctions we have seen in the epic genre. Accordingly, a folk ballad is anonymous but we can safely infer that there must have been a poet since all poems are mostly composed by individual poets. There is no first person singular (I), but where it stays in, it is always found in the context of the speech by identifiable characters in the poem to whom it refers. In studying the folk ballad, also studying the poetry of the traditional people as different from the poetry of art as in the art 
ballad whose writer, who may modify and use folk materials, is known. Thus, oral transmission is the medium of spreading the song of the folk ballad.

There are different sub-categories of the ballad which include the ballads of history, of love, of humor and of domestic tragedy. Others include ballads of the domestic border and ballads derived from epic materials.

Some common characteristic features of the ballad as a form of poetry as follows:

1. Impersonality and unsentimentality.

2. The anonymity of authorship and consequent lack of authorial comments

3. Simple repetition.

4. Incremental repetition meant to slow down the action and thus add to the suspense and emphasize the points in a dialogue.

5. Focus on a single episode.

6. Use of dialogue to make the action of story dramatic and compress and remove unnecessary descriptions and points.

7. Absence or minimal utilization of figures of speech.

8. Use of refrains which aids musicality in the poem as well as perform the functions of repetition noted above (in \#4).

9. Stereotype or stock epithets and concrete diction.

10. Quatrain stanzas.

As a general rule, the ballad uses a common measure of a four-line stanza rhyming abab; abcb or xaxa. You should note that in this rhyming pattern the first and third lines could rhyme (represented as ' $a$ ' in abab), while the second and fourth lines (represented as ' $b$ ') must rhyme. In some ballads, however, the first and third lines may not rhyme (as in abcb and xaxa, where ' $\mathrm{x}$ ' represents 'no rhyme' and this deviation does not disqualify such lines as ballad stanzas. The following are notable examples of the folk ballad and the art ballad which you should read in any good anthology of English poetry:

An ode is a rhymed or rarely unrhymed lyric poem often in the form of an address, expressive of exalted or enthusiastic emotion (usually of exalted style and enthusiastic tone), especially one of the varied or irregular meter. An ode is usually between 50 and 200 lines long and it was originally intended to be sung or at least recited. In its earliest Greek form established by the poet Pindar, it was choral or sung by a group of people who constituted the persons who moved in a dance rhythm in the dramatic poetry that was the main matrix for the ode or form.

In manner, the ode is an elaborate lyric, expressed in language dignified, sincere, and imaginative and intellectual in tone. Inform the ode is more complicated than most of the lyric types. Perhaps the essential distinction of form is the division into strophes: the strophe, antistrophe, and epode". The dance movements of the chorus are as follows:

trophy (movement to the left)

Antistrophe (movement to the right)

Epode (Chorus stands still).

The great period of the ode in English poetry began with Abraham Cowley (in Yesufu, A. R et al: 2006) who in the seventeenth century popularised the Pindaric ode in English. There are three main types of odes in English poetry, namely: the Pindaric (regular) the Horatian and the Irregular. The Pindaric ode is a complex poem of some length on a subject of public interest or on an abstract quality, written in rhyming or irregular pattern. On the other hand, the Horatian type modeled on the odes of the Roman poet Horace is less complex, calm, meditative and restrained and contain only one strophe (homostrophic).

The sonnet is a poem generally expressive of a single, complete thought, idea, or sentiment. It is made up of 14 lines, usually five-foot iambic pentameters, with lines arranged according to one of the certain definite rhyme schemes. Holman (in Yesufu, A. R et al: 2006) defines this poetic form as "a lyric form of fourteen lines, highly arbitrary in form, and following one or another of several rhyme schemes".

There are three main types of the sonnet; these are the Petrarchan or Italian, the Miltonic, the Shakespearean or Elizabethan. We should note that although the sonnet was originally an Italian poetic form, hence the name of the prototypic form - Petrarchan/Italian, it had a very large following in the English poetic tradition beginning from the sixteenth century.

1. Petrarchan/Italian: This type consists of two parts or systems as they are called - a major part known as the octave made up of the first eight lines, a minor part called the sestet made up of the last six lines. There is usually a pause or turn in an idea or thought at the end of the octave. This turn or break in a sense is known technically as the 'Volta'. This structure conventionally goes hand in hand with the 
thematic content of the poem in that a statement of a problem, a situation or an incident in the octave is followed by a resolution in the sestet. The rhyme scheme of the octave is: abba, abba and this is fixed or invariable. On the other hand, the rhyme scheme of the sestet varies, but it may consist of any arrangement of two or three rhymes as long as the last two lines do not form a couplet that is, they do not rhyme. Thus, the usual arrangement in the sestet is cdcdcd or cdecde. An example of this type in English poetry is William Wordsworth's "The World is too much with us".

2. Miltonic: This type is similar to the Italian form discussed above, but the only difference is that the Miltonic does not observe the pause or turn at the end of the octave; rather the poet lets the octave to run-on into the sestet. Suitable examples of this type are John Milton's "On His Blindness"; "On the late massacre at Piedmont" and Sonnet XXIII "Methought I saw my late espoused saint".

3. Shakespearean/Elizabethan/English: This type differs markedly from both the Petrarchan and Miltonic forms. It consists of three quatrains and a final rhyming couplet and its rhyme scheme is abab cdcd efef gg. At times the division of material found in the Petrarchan sonnet is also present here or there is repetition with a variation of the statement in the three quatrains with the final couplet presenting a neat and laconic encapsulation of the central thought in the poem. The volta sometimes occurs between the twelfth and thirteenth lines.

The following are examples of this type: "Shall I compare thee to a summer day?"; "Let me not to the marriage of true minds"; William Shakespeare's "Since Brass nor stone, nor earth, nor boundless sea"

An elegy is a sustained and formal poem setting forth the poet's meditations upon death or another solemn theme (Holman in Yesufu, A. R et al: 2006). The meditation is often occasioned by the death of a particular person, a painful loss or a general calamity that touches not just the poet as an individual but a wider spectrum of persons in his community or man generally. Other poetic types that are akin to the elegy and whose labels are often misused in reference to the elegy are the dirge, a short, less formal and usually in the form of a text to be sung, with sub-types such as threnody which is mainly an equivalent to the dirge and monody which is an elegy presented as an utterance by one person.

An ancient category of the elegy is the pastoral elegy in which the poet or mourner and the dead or the one mourned, who is also a poet, are characterized as shepherds. The name pastoral is derived from the Greek word pastor, which means shepherd. MH Abrams (in Yesufu, A. R et al: 2006), using one of the notable examples of the pastoral elegy, has identified seven fundamental conventions that have marked this poetic form from its earliest Greek form through the Renaissance as follows:

1. The invocation of the muses and frequent references to other figures from classical mythology.

2. All of nature is implicated or joins in mourning the shepherd's death.

3. The mourner charges with negligence the nymphs or other guardians of the dead.

4. There is a procession of mourners.

5. The poet raises questions about the justice of divine providence and goes on to comments on the decadence of his contemporary society in seeming digressions which are often integral to the development of the mourner's line of thought as in "Lycidas".

6. In Post-Renaissance elegies, flowers are brought in to deck the hearse in an elaborate passage.

7. There is a closing consolation, especially in Christian elegies, where the tone of the poem changes from that of grief and despair to joy and assurance and an epiphanic realization that death is a necessary prelude to a higher life.

In its original form, the lyric was a poem sung to the accompaniment of a lyre - a classical stringed musical instrument. In the Greek classical period, it was sung by a single singer and was thus differentiated from the 'choric', which was performed by a group of singers. The term is now applied to describe any poem that is light in tone, could be adapted into song and reflects the personal mood or feeling of the singer or poet rather than narrate a story.

This quality or characteristic constitutes the main difference between it as a poetic type and the ballad and the epic which concentrate on extra-personal subjects or themes. The lyric does not follow any rigid metrical law (unlike the sonnet) by which it is identified and it is for this reason that it is often regarded as a mode of writing rather than as a form.

The subjects of the lyric poet are as varied as his moods; thus he is at one time writing about love and at other times he is expressing his feelings towards nature or merely giving vent to his personal observations on life generally. However, the idea of the unity of mood, of thought, of feeling, and of style is essential to the lyric.

Since the true quality of the lyric is the personal element, that is, as a vehicle of the poet's mood, a means of expressing his individual sensibility, the ode, the sonnet as well as the elegy are lyrics. As such all the examples of these latter form cited in the preceding sections of this unit can rightly be studied as lyrics.

18 | ISLLAC : Journal of Intensive Studies on Language, Literature, Art, and Culture 


\section{METHOD}

In this research was adapted phenomenological research. This research located in Miligo Village, Cailaco administrative, Bobonaro Municipality. The subject of the research was the community in Meligo village that has experience in the culture especially related to the "lesu-lulf". Therefore, in this research, there were four informants that chosen to be investigated in this research.

Instruments in a research was a testing device for measuring a given phenomenon, such as a paper and test, a questionnaire, an interview, a research tool, or a set of guidelines for observation. In this research, the writer used an interview as the instrument. Interviews can be used to explore the views, experiences, beliefs, and motivations of individual participants.

Gill, P (2008) described the three fundamental types of research interviews, namely structured, semi-structured and unstructured. Structured interviews are, essentially, verbally administered questionnaires, in which a list of predetermined questions are asked, with little or no variation and with no scope for follow-up questions to responses that warrant further elaboration. Conversely, unstructured interviews do not reflect any preconceived theories or ideas and are performed with little or no organization. While Semi-structured interviews consist of several key questions that help to define the areas to be explored, but also allows the interviewer or interviewee to diverge in order to pursue an idea or response in more detail. In this research, the writer used structured interview which consists of 10 questions.

Primary data sources in this research were the scripts of "lesu-luli's poetry" and scripts of the records from the informants. While the secondary data source was the source text, such as literary theory books, the results of another literature research about poetry and culture, as well as the source from the internet. Furthermore, the data from this research was the result of the interview with the informants.

Data analysis techniques consist of three activities that occur simultaneously, namely data reduction, data presentation, and conclusions or verification. The analytical technique used an interactive analysis model and in the form of activities move on to all three processes of the research process.

\section{FINDINGS}

Many years ago, there was a village namely Meligo that was located in Cailaco administrative, Bobonaro Municipality. In this village, there was a sacred stone that believed by the community able to bring the blessing. It was called "lesu-luli". Beside the sacred stone, in this village, there were several sacred houses. Timor Leste's people called it uma lisan or uma lulik. The eight of uma lisan or uma lulik in this village were: uma Slelo, uma Bere Ubu, uma Bere Mau, uma Osu Ubu, uma Vito, uma Acu Lete and Uma Lale include lesu-luli.

The name of lesu luli coming from the name of an ancestor in Miligo village. It was told that the lesu luli came from the name of two grandfathers namely Mau Lesu and he came from uma Slelo (uma lisan), while another one was Lesu Tali, he came from uma Bere Ubu (uma lisan). Both of the grandfathers were a captain and a major. They had played the important role to struggle and liberate for the tradition of lesu luli. This struggle involved the eight households (that now become the eight of uma lisan or uma lulik) and also the kings. The kings were two peoples namely Talentu and Kornel. Talentu came from uma Bero Mau while Kornel came from uma Kali Ubu. After involving the eight households and the two kings, they both also built up the security around lesu - luli, while both of them fought from the district Manu Fahi up to Oe-Cusse. At the moment, uma Bito has a role as police and uma Kabu have a role as the leader of the security. Even though both these uma lisan have the role as police and the leader but they still have to respect to uma Slelo because it is in control to give an order it means that if they orders to catch or be punished then it must be done.

Based on the story above, it can be seen that in the ancestors time even the government not independent yet but they independent already. It means that the lesu - Iuli already exist before the independence of Timor Leste. Until the moment, in Meligo village uma Slelo was the leader. Therefore, in the ceremony lesu - Iuli it played the role to express the lesu-Iuli' poetry (or in Tetum called "hamulak"). In the ceremony also, normally there were several worships needed for the ceremony such as buah malus, tua, animal moris (bibi, fahi no manu).

The ceremony of lesu luli was conducted every year. This ceremony was aimed to asked the blessed from the God and the ancestors. It must be celebrated every year because the community in Meligo village believed that culture is the foundation of human life and the spirit was a prayer, therefore it would cause death, lack of seeds, drought, and got disaster. Because they believed in the struggle of the ancestors in realizing the lesu-luli itself. Otherwise, if they were conducted the ceremony they would keep away from the death, disaster, and drought.

Poetry is a literary work that has a very complex structure which consists of several levels. 
1) Structure: In the structural analysis, the writer identified the elements that usually presented in a poem as accurately as possible. First, in lesu-Iuli's poetry there was a line. A line is a unit of language into which a poem or play is divided, which operates on principles which are distinct from and not necessarily coincident with grammatical structures, such as the sentence or single clauses in sentences. The second, in lesu - luli's poetry there was a stanza. Stanza is a group of lines in a poem. There were seven types of stanza, namely couplet (a two line stanza), triplet (a three-line stanza), quatrain (a four-line stanza), cinquain/quintet (a five-line stanza), sestet (a six-line stanza), septet (a seven line stanza) and octet/octave (an eight-line stanza). The types of stanza found in lesu-Iuli's poetry were three types; namely the triplet, the quatrain and the cinquain/quintet.

2) Sound: Poets had many tools that could be used to create a poem. The one that might be the most familiar with was the effect of sound. The most recognizable sound effect used in poems was the first rhyme. A rhyme meant when two words have a similar ending sound in the end. There were two types of rhyme, namely internal rhyme and end rhyme. Internal rhyme means rhyming within the same line of a poem. While end rhyme means rhyming words at the ends lines in a poem.

3) Figurative language or diction: As a literary device, diction refers to the choice of words and style of expression that an author/ poets made and used in a work of literature. Diction can have a great effect on the tone of a piece of the poem and how readers perceive the characters. One of the primary things that diction does was establish whether a work is formal or informal. Choosing more elevated words will establish a formality to the piece of the poem while choosing slang will make it informal. style of language or diction that found in lesu - Iuli's poetry was a formal language. It could be seen that the selection of words in this poem was very religious. "Tais Lulf" is a symbol of worship to the ancestors when the reader (lia nain) was reading the lesu-luli'spoetry.

\section{DISCUSSION}

Culture means different things to different people. Usually, we think of material things that may seem to stereotype people to a specific group or culture. Culture gives us appropriate models for marriage and family structures; it teaches us what to eat or not eat; it is about the institutions we all frequent such as school, church, hospital, or Facebook. Many people believe culture is about going to the opera or the ballet, or knowing which works of art depict what, but in reality, culture is simply about everyday life. It is about what time people awake in the morning and everything else each person does until he/she retires to bed each night. In fact, culture is also about what kind of bed individuals and families sleep in, and who they sleep with.

Based on the finding of the research above it can be seen that "small things can become bigger". The efforts of the ancestors in Meligo village end by a legacy that are now become an important part of people in this village. It means that the struggle from the ancestors able to give a big contribution to all the grandchild in Meligo village. People in Meligo village believe that by conducting the ceremony, the village will always get the blessings of the God and the ancestors. While using Lesu - Luli's poetry seemed like a beautiful song to the ancestors to accompany the ceremony.

Lesu - Luli's poetry itself, based on the writer finding in the analysis this poetry met some intrinsic elements of poetry such as (1) Structure. In the structural analysis, the writer found two elements line and stanza. The types of the stanza in lesu - luli's poetry were a triplet, the quatrain, and the cinquain/quintet stanza. (2) Sound. The most type of sound found in lesu - Iuli's poetry was ended rhyme sound. (3) Figurative language or diction. The style of language or diction that found in lesu - luli's poetry was a formal language and the selection of words in this poem was very religious.

Therefore, culture is about how people earn a living, where and how each of us acquires food. It is how people do their laundry or get the water they drink. It is also about those unspeakable topics like toilet facilities, and the hygiene practices that are part of such necessary daily routines. In other words, lives are all about culture. That is why even though the globalization forces continue to escalate cultural changes everywhere, but it is very expected that it will never affect the communities to protect and respect the culture.

\section{CONCLUSIONS}

The history of "lesu-luli" in Meligo village. Based on the story from the first, second and third narrator, the name of lesu - Iuli coming from the name of two grandfathers namely Mau Lesu and Lesu Tali. Mau Lesu came from uma Slelo while Lesu Tali came from uma Bere Ubu. Both of the grandfathers were a captain and a major. They had played the important role to struggle and liberate for the tradition of lesu Iuli. This struggle involved the eight households (that now become the eight of uma lisan or uma lulik) and also the kings. The kings were two peoples namely Talentuand Kornel. Talentu came from uma Bero Mau 
while Kornel came from uma Kali Ubu. Lesu - Iuli was a sacred stone that until now exist in Meligo village. It was not only a sacred stone without meaning because peoples in Meligo village made this place as a place where the people could ask the blessing of the ancestors and God. This was a culture and tradition that regularly conducted every year around September or October. Peoples in Meligo village believed that if the ceremony of lesu - Iuli was not celebrated, it would cause died, disaster, bad seeds, and drought (dry season). There were several intrinsic elements found in lesu - Iuli's poetry, namely: structure, sound, figurative language or diction,

Education values such as social, cultural, humanities, religious and moral found in the history of lesu - luli and its poetry are very beneficial to be embedded in the younger generation. It is able to give motivation so it could educate people to be respected and always protect the culture which has existed for many years.The history of lesu - luli and its poetry could become a reference especially for the lecturer who teaches English literature in exploring the culture in Timor Leste. It was also expected given the insight into the variety of culture which has existed for many years in Timor Leste.

\section{REFERENCES}

Baer, W. (2006). Writing Metrical Poetry: Contemporary Lessons for Mastering. Accessed on August, 8th 2017 from https://books.google.com.

Gill, P. (2008). Methods of data collection in qualitative research: interviews and focus. Accessed on August, 8th 2017 from www.nature.com

Klarer, M. (2004). An Introduction to Literary Studies 2nd Edition. London and New York: published by Routledge 11 New Fetter Lane, London EC4P 4EE.

Osakwe, E. (2015). The Nature of Poetry in Literature. Accessed on August, 8th 2017 from https://schoolnewsngr.com.ng.

Puspitoningrum, E., \& Rahmayantis, M. D. (2017). Introducing “ Undha Usuk” Javanese Language Through Children Drama Performance in Festival Kampoeng Pejoeang at Trate, Ngadiluwih. ISLLAC: Journal of Intensive Studies on Language, Literature, Art, and Culture, 1(2), 41-46.

Robert F. Accessed on August, 8th 2017 from https://www.goodreads.com.

Sari, Y. (2014). Chapter II Review Of Related Literature. Accessed on August, 8th 2017 from repo.iaintulungagung.ac.id.

Sugiyono. (2011). Metode Penelitian Kuantitatif, Kualitatif dan Kombinasi (Mixed Methods). Penerbit Alfabeta: Bandung.

Wallace, B. Doris, and Howard E. Gruber. (1992). Creative People at Work: Twelve Cognitive Case Studies. Accessed on August, 8th 2017 from https://books.google.tl.

Yesufu, et al. (2006). Introduction to Poetry. National Open University of Nigeria: Nigeria.

Yesufu, et al. (2008). Cambridge Advanced Learner's Dictionary 3rd Edition. Cambridge University Press: UK. 